\title{
Spontaneous Clavicle Fracture in Beta Thalassemia Major
}

\author{
Merchant RH', Doctor $\mathrm{PN}^{2}$, Choudhari $\mathrm{AK}^{3}$ and \\ Pandey AR ${ }^{4 *}$ \\ ${ }^{1}$ Department of Pediatrics, Nanavati Super Speciality \\ Hospital, Mumbai, India \\ ${ }^{2}$ Resident, Children's Hospital of Michigan, US \\ ${ }^{3}$ Department of Radiology, Nanavati Super Speciality \\ Hospital, Mumbai, India \\ ${ }^{4}$ Nanavati Super Speciality Hospital, Mumbai, India \\ *Corresponding author: Pandey AR, M.B.B.S. Intern, \\ Nanavati Super Speciality Hospital, SV Road, Vile-Parle \\ (West), Mumbai-56, Maharashtra, India
}

Received: January 25, 2019; Accepted: February 27, 2019; Published: March 06, 2019

\section{Case Report}

A 20-year-old male with beta-thalassemia major presented with a sudden spontaneous swelling over the left clavicle with no history suggestive of trauma. Four years ago, he had developed idiopathic focal segmental glomerulosclerosis, which progressed to chronic renal failure. Three months earlier he had a hypocalcaemic seizure with serum total calci-um of $5.3 \mathrm{mg} / \mathrm{dl}$ and serum 25-hydroxy Vitamin D of $5 \mathrm{mg} / \mathrm{ml}$. Dual-energy X-ray absorptiometry done revealed osteo-porosis with a $\mathrm{T}$ score of 2.8. Physical examination showed restriction of movement of left arm and shoulder due to pain, the swelling measured $5 \times 4 \times 2 \mathrm{~cm}$ (Figure 1), was firm in consistency, with tenderness over the left clavicle, it was not fluctuant or pulsatile and did not transilluminate. A diagnosis of hematoma was suspected. Chest X-ray was normal, however, Zanca view of the clavicle detected a minimally displaced fracture between the proximal and middle third of the left clavicle along with osteoporosis of the humerus (Figure 2). Magnetic resonance imaging showed a minimally displaced fracture of the left clavicle with a hematoma arising from the fracture site extending into upper fibres of pectoralis major with no injury to neurovascular bundles (Figure $3 \mathrm{a} \& \mathrm{~b}$ ). The patient was managed conservatively with pain control, ice application and figure of eight bandages, besides receiving oral 25-hydroxy Vitamin D3 and oral alendronate to improve bone mineral density and prevent recurrence of fracture. He has subsequently recovered completely.

\section{Discussion}

Osteopathy in Thalassemia Major (TM) has emerged as a prominent cause of morbidity, [1] and several factors are implicated in the reduction of bone mass, such as delayed sexual maturation, Growth Hormone (GH) and insulin growth fac-tor-1 deficiency, parathyroid gland dysfunction, ineffective hemopoiesis with progressive marrow expansion, direct iron toxicity on osteoblasts, and chronic liver disease [2,3]. Musculoskeletal manifestations of beta thalassemia that are commonly seen include fractures, thalassemic osteoarthropathy and drug-related side effects of patients on treatment with iron chelators. Children and adolescents sustain more fractures than adults, as a result of minor, direct or indirect trauma, especially in the more severe variety of beta thalassemia major [4].

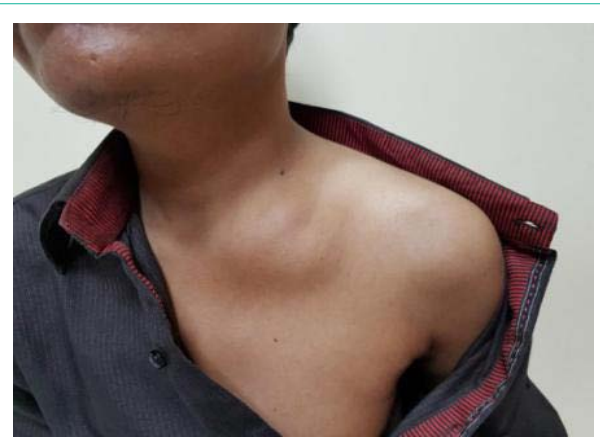

Figure 1: 20-year-old male with swelling over the medial and middle third of the left clavicle.

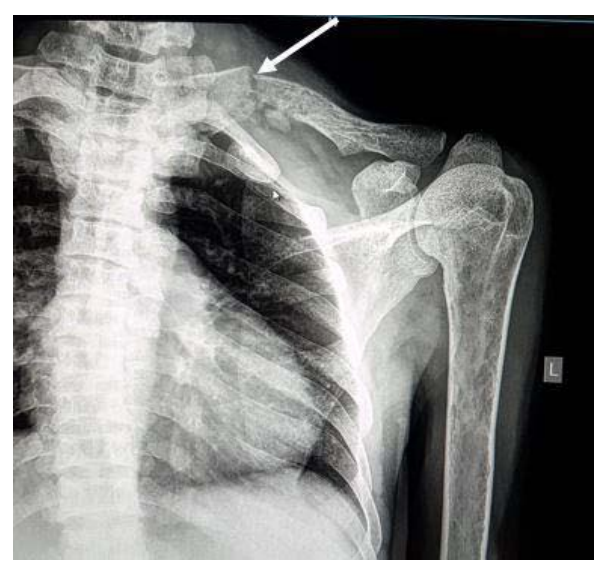

Figure 2: Zanca view of the clavicle detected a minimally displaced fracture between the proximal and middle third of the left clavicle along with osteoporosis of the humerus.

Majority of patients with thalassemia have low bone mineral density and experience lifelong fracture rates as high as 71\%, [5] however, spontaneous fracture of the clavicle has not been reported earlier. We present a case of an adult beta thalassemia major who presented with a hematoma due to an underlying spontaneous fracture of the clavicle confirmed on MRI imaging. Bone mineral density should be evaluated regularly for early diagnosis of osteoporosis to prevent
Citation: Merchant RH, Doctor PN, Choudhari AK and Pandey AR. Spontaneous Clavicle Fracture in Beta Thalassemia Major. Ann Hematol Oncol. 2019; 6(4): 1241. 


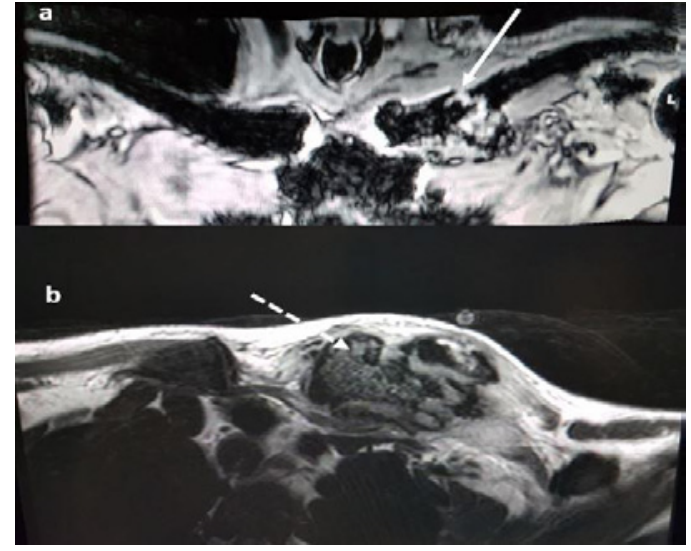

Figure 3: (a) Magnetic resonance tomography gradient sequence showing a minimally displace fracture between proximal and middle third of the left clavicle. (b) Magnetic resonance tomography gradient sequence showing hematoma arising from the fracture site measuring $3.5 \times 3.3 \times 3.2 \mathrm{~cm}$ extending into upper fibres of pectoralis major and beneath the sternocleidomastoid.

morbidity [6]. Optimal transfusion and chelation therapy reduces the severity of bone fragility and deformity. Bisphosphonates, which have a good profile of safety \& tolerability and have been shown to improve bone mineral density, reduce bone turnover, and decrease bone pain in patients with thalassemia-associated osteoporosis [7].

\section{References}

1. Phillip Wong, Peter J Fuller, Matthew T Gillespie, Frances Milat. Bone Disease in Thalassemia: A Molecular and Clinical Overview, Endocr Rev. 2016; 37: 320-346.

2. Toumba M, Skordis N. Osteoporosis Syndrome in Thalassaemia Major: An Overview. Journal of Osteoporo-sis. 2010; 2010.

3. Dede AD, Trovas G, Chronopoulos E. Thalassemia-associated osteoporosis: a systematic review on treatment and brief overview of the disease. Osteoporos Int. 2016; 27: 3409-3425.

4. Praveen L Basanagoudar, Shivinder S Gill, Mandeep S Dhillon, Ram K Marwaha. Fractures in Transfusion Dependent Beta Thalassemia-An Indian Study. Singapore Med J. 2001; 42: 196-199.

5. Baldini M, Forti S, Marcon A, Uliveri FM, Osatti A, Tampieri B, et al. Endocrine and bone disease in appropriately treated adult patients with betathalassemia major. Ann Hematol. 2010; 89: 1207-1213.

6. Merchant R, Udani A, Puri V, D'cruz V, Patkar D, Karkera A. Evaluation of osteopathy in thalassemia by bone mineral densitometry and biochemical indices.Indian J Pediatr. 2010; 77: 987-991.

7. Giusti A, Pinto V, Forni GL, Pilotto A. Management of beta-thalassemiaassociated osteoporosis. Ann NY Acad Sci. 2016; 1368: 73-81.
Ann Hematol Oncol - Volume 6 Issue 4 - 2019

ISSN : 2375-7965 | www.austinpublishing group.com

Pandey et al. () All rights are reserved
Citation: Merchant RH, Doctor PN, Choudhari AK and Pandey AR. Spontaneous Clavicle Fracture in Beta Thalassemia Major. Ann Hematol Oncol. 2019; 6(4): 1241. 